\title{
Origins and genetic features of the Okhotsk people, revealed by ancient mitochondrial DNA analysis
}

\author{
Takehiro Sato - Tetsuya Amano - Hiroko Ono • \\ Hajime Ishida · Haruto Kodera · Hirofumi Matsumura • \\ Minoru Yoneda $\cdot$ Ryuichi Masuda
}

Received: 27 March 2007/ Accepted: 11 May 2007/Published online: 14 June 2007

(C) The Japan Society of Human Genetics and Springer 2007

\begin{abstract}
In order to investigate the phylogenetic status of the Okhotsk people that were distributed in northern and eastern Hokkaido as well as southern Sakhalin during the fifth to the thirteenth centuries, DNA was carefully extracted from human bone and tooth remains excavated from archaeological sites. The hypervariable region 1 sequences of the mitochondrial DNA (mtDNA) control region were successfully amplified and $16 \mathrm{mtDNA}$ haplotypes were identified from 37 individuals of the Okhotsk people. Of the 16 haplotypes found, 6 were unique to the Okhotsk people, whereas the other 10 were shared by northeastern Asian people that are currently distributed
\end{abstract}

T. Sato $\cdot$ R. Masuda $(\square)$

Graduate School of Science, Hokkaido University,

Sapporo 060-0810, Japan

e-mail: masudary@ees.hokudai.ac.jp

T. Amano $\cdot$ H. Ono

Hokkaido University Museum, Sapporo 060-0810, Japan

H. Ishida

Faculty of Medicine, University of the Ryukyus,

Nishihara 903-0215, Japan

H. Kodera

School of Dental Medicine, Tsurumi University,

Yokohama 230-8501, Japan

H. Matsumura

Sapporo Medical University, Sapporo 060-8556, Japan

M. Yoneda

Graduate School of Frontier Sciences, University of Tokyo,

Kashiwa 277-8562, Japan

R. Masuda

Creative Research Initiative "Sousei", Hokkaido University,

Sapporo 060-0810, Japan around Sakhalin and downstream of the Amur River. The phylogenetic relationships inferred from mtDNA sequences showed that the Okhotsk people were more closely related to the Nivkhi and Ulchi people among populations of northeastern Asia. In addition, the Okhotsk people had a relatively closer genetic affinity with the Ainu people of Hokkaido, and were likely intermediates of gene flow from the northeastern Asian people to the Ainu people. These findings support the hypothesis that the Okhotsk culture joined the Satsumon culture (direct descendants of the Jomon people) resulting in the Ainu culture, as suggested by previous archaeological and anthropological studies.

Keywords Okhotsk people - Genetic origins - Ancient DNA · Mitochondrial DNA · Molecular phylogeny

\section{Introduction}

The Okhotsk culture developed around southern coastal regions of the Okhotsk sea, including Hokkaido, Sakhalin and the Chishima (Kuril) archipelago, during the fifth to the thirteenth centuries (Amano 2003a). The feature most specific to Okhotsk culture is the lifestyle-adapted to fishing and hunting - and the restriction of locations of archaeological sites to coastal regions. In addition, polygonal large houses and rituals using animals such as brown bears and sea mammals are also specific to the Okhotsk culture. This culture is clearly different from the Epi-jomon culture (third century BC to seventh century AD) and the Satsumon culture (eighth to fourteenth centuries; Amano 2003b), which were contemporary with the Okhotsk culture and developed in southern and inner parts of Hokkaido.

Many human skeletal remains have been excavated from archaeological sites of the Okhotsk culture in Hokkaido 
and Sakhalin. Skeletons of the Okhotsk people share particular morphological characteristics: high and round neurocranium, large mandible, flat face, and extremely shallow canine fossa. Kodama (1948) reported that these characters were similar to those of the Aleut people among neighboring populations. On the other hand, Suzuki (1958) reported that the Okhotsk people were morphologically closer to the Eskimo people than the Aleut. Mitsuhashi and Yamaguchi (1961) found that skeletons of the Okhotsk people have characteristics specific to those of northeastern Asian people. These studies revealed that the morphological characteristics of the Okhotsk people were clearly different from those of the Ainu people currently living in Hokkaido. In addition, the morphological characteristics of the Okhotsk people are similar to those of the Nivkhi and Ulchi people that are currently distributed around Sakhalin and downstream of the Amur River (Yamaguchi 1974; Ishida 1988, 1996; Kozintsev 1990, 1992). The final conclusion of the anthropological status of the Okhotsk people, however, has not yet been determined.

On the other hand, evidence of the occurrence of bearsending ceremonies, as also seen in the Ainu culture, was found from archaeological sites of the Okhotsk culture (Utagawa 2002). In many cases, the skulls of brown bears were enshrined in bone mounds located within houses of the Okhotsk culture. This is a special custom that is not seen in archaeological sites of other cultures in Japan. The ritual is thought to be a proto-type of "Iomante', which was performed as a bear-sending ceremony in the Ainu culture. Ancient DNA analysis of the skulls of brown bears, excavated from an Okhotsk culture site on Rebun island, northern Hokkaido, showed that there were cultural exchanges through bear cubs between the Okhotsk people and the Epi-jomon people (Masuda et al. 2001), which are archaeologically considered to be direct descendants of the Jomon people, and lived from the third century BC to the seventh century AD in southern Hokkaido. However, the custom of enshrining bears did not occur in the Satsumon culture followed by the Ainu culture. These facts suggest that the Okhotsk culture joined the Satsumon culture in Hokkaido, resulting in establishment of the Ainu culture (Utagawa 2002).

Clarification of the origins and descendants of the Okhotsk people is essential to further understanding of the anthropological history and phylogenetic relationships among native people in northeastern Asia including Hokkaido. Therefore, in the present study, ancient mitochondrial DNA (mtDNA) analysis of human skeletal remains excavated from archaeological sites of the Okhotsk culture in Hokkaido and Sakhalin was performed. The molecular phylogenetic features of the Okhotsk people were then compared with those of modern native populations of northeastern Asia. The genetic origins of the Okhotsk people, and the relationships between the Okhotsk people and the Ainu, are discussed.

\section{Materials and methods}

Sample collection

To analyze mtDNA sequences of the Okhotsk people, 78 skeletal remains excavated from seven archaeological sites in Hokkaido and Sakhalin (Fig. 1) were used. The skeletal remains were preserved in the Hokkaido University $\mathrm{Mu}$ seum and Sapporo Medical University. To avoid duplicate analysis of skeletal remains from single individuals, parts in the same positions of bones, or bones from different graves within one archaeological site were used.

Because skulls from the Moyoro site, which were preserved at the Hokkaido University Museum, lacked archaeological information, their dates were determined by the radiocarbon method (Yoneda et al. 2004), and found to be dated from the seventh to the thirteenth centuries $A D$, with the marine calibration and local correction to the marine reservoir effect (400 14C years). These dates were in agreement with the Okhotsk culture period. The remains preserved at the Sapporo Medical University shared archaeological and morphological information indicating that they were obviously people of the Okhotsk culture.

\section{DNA extraction}

Ancient DNA was extracted from osteocytes of femurs, ribs, coxal bones, skulls, or sacrums, or cells in dentin tubules of teeth (molars or premolars) of the maxilla or mandible. To

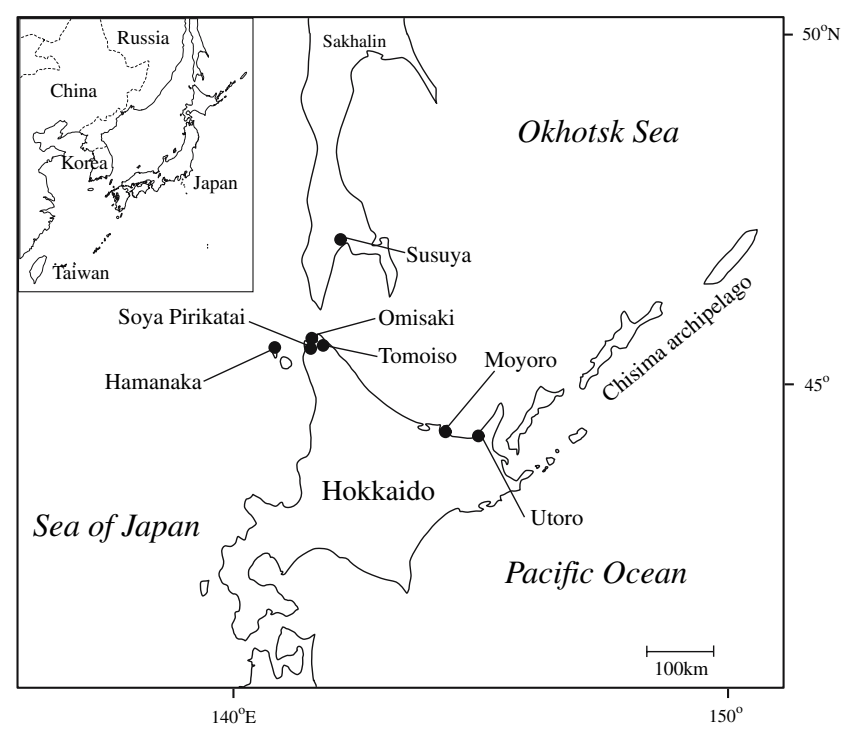

Fig. 1 Geographical locations of archaeological sites of the Okhotsk culture, where specimens of the present study were excavated 
remove possible surface contamination of external DNA, each bone piece or tooth was soaked in sodium hypochlorite solution (Nacalai) for $5 \mathrm{~min}$, rinsed with DNase-/RNasefree distilled water, and allowed to air-dry. Using a dental drill, bone or tooth powders were then obtained from the samples. Extraction of DNA from bone or tooth powders was carried out according to the method of Masuda et al. (2001). Approximately $0.2-0.5$ g powder per specimen was decalcified with $30 \mathrm{ml} 0.5 \mathrm{M}$ ethylenediamine tetraacetic acid (EDTA, Nippongene) in a 50-ml plastic tube with rotation at room temperature for $24 \mathrm{~h}$. The decalcified pellets were then suspended in $5 \mathrm{ml} 0.5 \mathrm{M}$ EDTA containing $100 \mu 110 \mathrm{mg} / \mathrm{ml}$ proteinase $\mathrm{K}$ at $37^{\circ} \mathrm{C}$ overnight with rotation. The solution was extracted using the phenolchloroform extraction method (phenol/chloroform/isoamyl alcohol, 25:24:1; Sambrook et al. 1989). The extracts were concentrated into approximately $100 \mu \mathrm{l}$ TE buffer using VivaSpin 6 Concentrators (Sartorius) and submitted to polymerase chain reaction (PCR) as detailed below.

Amplification and nucleotide sequencing

A segment of the mtDNA hypervariable region 1 (HVR1, nucleotide positions 16,121-16,569, relative to the Cambridge reference sequence, CRS; Anderson et al. 1981) for each sample was PCR-amplified and sequenced. Because of fragmentation of aged DNA, a 449 base-pair (bp) fragment was divided into three overlapping sub-regions (fragments 1-3) and amplified with PCR primers L16120/H16239 (Adachi et al. 2004) for fragment 1, A16208/B16403 (Horai et al. 1989) for fragment 2, and A16401 (5'-AGATAGGGGTCCCTTGACC-3')/B00001 (5'-AGGGTGATAGACCTGTGATC-3') for fragment 3. Primers A16401 and B00001 were newly designed for the present study.

An aliquot $(1 \mu \mathrm{l})$ of DNA extract was used as template for PCR. The Multiplex PCR kit (Qiagen) was used for efficient PCR amplification. The PCR amplification was carried out in $20 \mu \mathrm{l}$ reaction mixtures containing $1 \times$ Multiplex PCR Master Mix, $0.25 \mu \mathrm{M}$ of each primer, and $0.4 \mu \mathrm{g} / \mu \mathrm{l}$ bovine serum albumin (BSA, Boehringer). The BSA was used to eliminate some effects of the PCR inhibitors that are often found in aged bone or tooth remains. Cycling parameters for PCR were $95^{\circ} \mathrm{C}$ for $15 \mathrm{~min}$, followed by 35 cycles of $94^{\circ} \mathrm{C}$ for $30 \mathrm{~s}, 55^{\circ} \mathrm{C}$ for $90 \mathrm{~s}$, $72^{\circ} \mathrm{C}$ for $90 \mathrm{~s}$, and 1 cycle with $72^{\circ} \mathrm{C}$ for $10 \mathrm{~min}$. All PCR amplifications were carried out in a PCR thermal cycler TP400 or TP600 (Takara).

An aliquot $(4 \mu \mathrm{l})$ of the PCR product was checked on a $2 \%$ agarose gel, and the remaining $(16 \mu \mathrm{l})$ was then purified with the QIAquick PCR purification kit (Qiagen), and used as template for direct nucleotide sequencing. Sequencing reactions were performed using the Thermo
Sequenase Primer Cycle sequencing kit (Amersham) and newly designed sequencing primers: A16126 (5'-CCAGCC ACCATGAATATTGT-3') and B16233 (5'-TGGAGTTGC AGTTGATGTGT-3') for fragment 1 , A16214 (5'-GCTTA CAAGCAAGTACAGC-3') and B16398 (5'-TTTCACGG AGGATGGTGGTC-3') for fragment 2, A16407 (5'-GGGT CCCTTGACCACCATC- $3^{\prime}$ ) and B16564 (5'-ATAGACCT GTGATCCATCGT-3') for fragment 3 . The $3^{\prime}$ ends of primers were labeled with Texas Red. These primers were designed on the basis of the CRS (Anderson et al. 1981). Cycling parameters were $95^{\circ} \mathrm{C}$ for $4.5 \mathrm{~min}$, followed by 30 cycles with $94^{\circ} \mathrm{C}$ for $30 \mathrm{~s}, 55^{\circ} \mathrm{C}$ for $30 \mathrm{~s}, 72^{\circ} \mathrm{C}$ for $1 \mathrm{~min}$, and 1 cycle with $72^{\circ} \mathrm{C}$ for $7 \mathrm{~min}$. The cycle PCR products were then applied to an automated sequencer (Hitachi SQ-5500).

\section{Contamination precaution}

The following standard contamination precautions were employed: separation of pre- and post-PCR experimental areas, wearing gloves, face masks and laboratory coats, use of disposable filter-plugged pipette tips and disposable tubes, treatment with a DNA contamination removal solution (DNA-AWAY, Molecular BioProducts), ultraviolet irradiation of equipments and bench, negative extraction controls, and negative PCR controls. Moreover, mtDNA HVR1 sequences of 19 persons (members of our laboratory and related archaeologists and anthropologists, whose origins are considered to be the Honshu island of Japan) were determined using DNA extracted from their hair roots. Extractionof DNA from hair roots was by the method of Walsh et al. (1991) and procedures for PCR and nucleotide sequencing were the same as above. When ancient DNA sequences from the Okhotsk remains were found to be identified with any modern DNA sequences, they were excluded from subsequent data analysis. In addition, two PCR amplifications from each sample were made to assess the reproducibility of the resultant sequences. Samples that did not show reproducibility were also excluded from data analysis.

\section{Data analysis}

The nucleotide sequences obtained were aligned using ClustalW (Thompson et al. 1994). The ancient DNA data were compared with previously reported sequence data of modern Asian people deposited in the DDBJ/EMBL/GenBank. A total of 1,019 mtDNA sequences (Fig. 2) were cited as follows: 51 Ainu people, 64 Korean and 65 Taiwan Han (Horai et al. 1996); 110 Koryak, 35 Even, 61 Buryat, 57 Nivkhi, 60 Northern Han, 82 Honshu-Japanese, 104 Kyushu-Japanese, 45 Okinawa-Japanese, 59 Philippine, 52 Malaysian and 54 Indonesian (Tajima et al. 2004); 87 
Fig. 2 Locations of Asian populations compared with the Okhotsk people in the present study. KRY Koryak, EVN Even, $B U R$ Buryat, $N V K$ Nivkhi, NTH Northern Han, KOR Korean, $J P H$ Honshu-Japanese, JPK Kyushu-Japanese, $J P O$ Okinawa-Japanese, $T W H$ Taiwan Han, PHL Philippine, $M A L$ Malaysian, IDN Indonesian, $O K H$ Okhotsk people

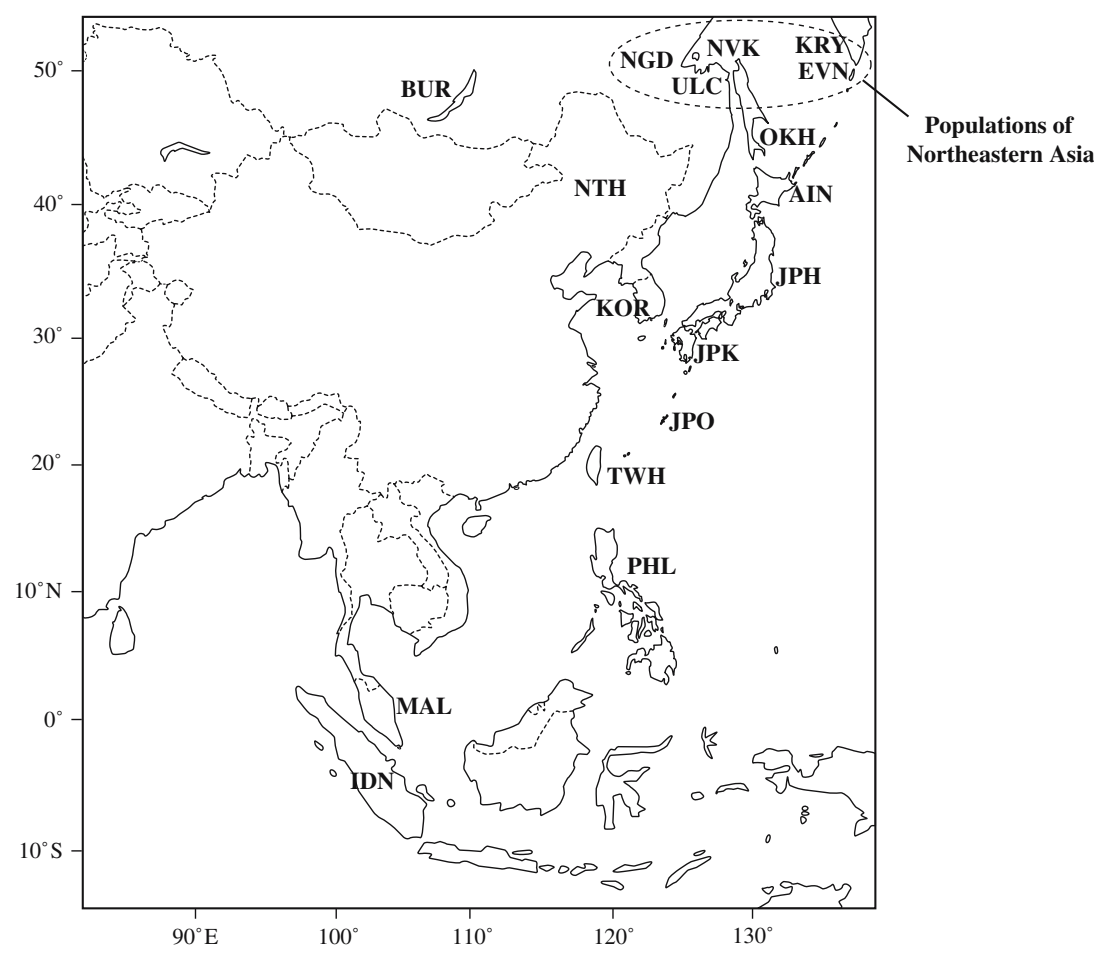

Ulchi and 33 Negidal (Straikovskaya et al. 2005). A phylogenetic tree for local populations was constructed with net nucleotide diversities ( $d_{\mathrm{A}}$ distances) between populations (Nei and Li 1979) and using the two-parameter model of nucleotide substitutions (Kimura 1980). Nucleotide diversity within and between populations $\left(d_{\mathrm{X}}\right.$ and $d_{\mathrm{XY}}$, respectively) and net nucleotide diversity between populations $\left(d_{\mathrm{A}}\right)$ were computed with the SENDBS program (provided by N. Takezaki). A phylogenetic tree was then constructed from the matrix of pairwise $d_{\mathrm{A}}$ distances using the neighbor-joining (NJ) method (Saitou and Nei 1987). The sequences of the African population (Vigilant et al. 1991) were used as an outgroup. The reliabilities of internal branching were analyzed by the bootstrap method (Felsenstein 1985) with 1,000 replications. Genetic relationships among the 17 Asian populations were determined using the multidimensional scaling method (Sneath and Sokal 1973) in STATISTICA version 03J (Statsoft JAPAN).

\section{Results}

MtDNA haplotypes identified from the Okhotsk people

Fragments 1-3 of the mtDNA control region HVR1 were successfully PCR-amplified from 47 of 78 specimens excavated from seven archaeological sites (Fig. 1) of the Okhotsk culture. No successful results were obtained from the other 31 samples, probably because of DNA degrada- tion. A total of $438 \mathrm{bp}$ was then sequenced for each of the 47 samples, since the portion located between nucleotide positions 16,121 and 16,131 could not be sequenced due to a polycytosine region at nucleotide positions 16,184 16,193 .

About 15 mtDNA haplotypes were identified from 19 modern individuals (members of our laboratory and related archaeologists and anthropologists, whose origins are thought to be the Honshu island of Japan). Because the comparison between the modern persons and the Okhotsk people showed that a haplotype from one modern person was shared by three Okhotsk people, that haplotype was excluded from subsequent data analysis to avoid problems of contamination by modern DNA. Moreover, because seven sequences from the Okhotsk people did not show reproducibility of PCR amplification or sequencing, they were also excluded from data analysis. As a result, 16 haplotypes identified from 37 Okhotsk specimens were reliable (Table 1) and used for subsequent analysis. The mtDNA nucleotide sequences of the Okhotsk people having specimen numbers will appear in the DDBJ database with the following accession numbers: AB292314AB292350.

Frequencies of $16 \mathrm{mtDNA}$ haplotypes identified from the Okhotsk people in modern Asian populations

The 16 mtDNA haplotypes identified from 37 Okhotsk people were compared with haplotypes of 1,019 individuals from 16 modern Asian populations. About six haplotypes 
Table 1 Nucleotide substitutions observed in mitochondrial DNA (mtDNA) haplotypes of the Okhotsk people examined in the present study

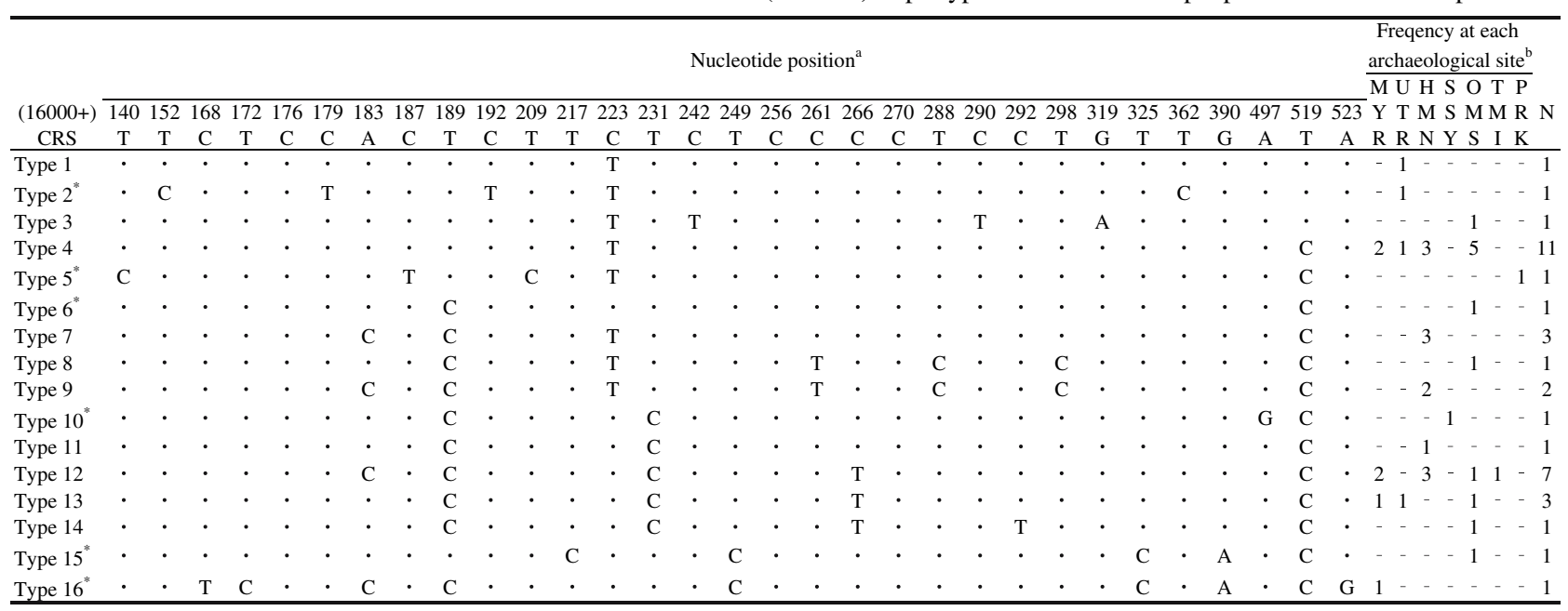

a All polymorphic sites are numbered according to the Cambridge Reference Sequence, CRS (Anderson et al. 1981). Only polymorphic sites in 438 bp were shown. Dots indicate identities with CRS

b Archaeological sites: MYR, Moyoro; UTR, Utoro; HMN, Hamanaka; SSY, Susuya; OMS, Omisaki; TMI, Tomoiso; PRK, Soya Pirikatai; N, Number of individuals with that haplotype

* Haplotypes which were found from only the Okhotsk people

(types 2, 5, 6, 10, 15, 16) were specific to the Okhotsk people and not found in any of the compared Asian populations (Table 1). No nucleotide substitutions common to all six specific haplotypes were found.

The other ten haplotypes (types 1, 3, 4, 7, 8, 9, 11, 12, $13,14)$ were shared by the people of other Asian populations at various frequencies (Table 2). Haplotypes from the Okhotsk people were especially shared by Nivkhi (43\%), Ulchi (38\%), Koryak (40\%) and Negiadal (39\%) with higher frequencies. Interestingly, $16 \%$ of the Ainu people shared 5 haplotypes (types 1, 3, 4, 7 and 12) with the Okhotsk people (Table 2); this value is relatively higher compared with other populations with the exception of northeastern Asian populations (Fig. 2).

Molecular phylogenetic relationships between the Okhotsk people and modern Asian populations

To investigate the phylogenetic relationships between the Okhotsk people and modern Asian populations, the NJ relationships among the 17 Asian populations were constructed (Fig. 3). In this phylogenetic tree, the Okhotsk people were clustered with the Nivkhi, Ulchi, Negidal, Koryak, and Even. Among them, the Nivkhi and Ulchi were much closer to the Okhotsk people, and clustered with more than $70 \%$ bootstrap values. The close relatedness among the three populations was in congruence with the high degree of sharing of mtDNA haplotypes. On the other hand, the Ainu people were phylogenetically distant from the Okhotsk people (Fig. 3). However, the $d_{A}$ distance
$(0.068 \%$, Table 3) between the Okhotsk people and the Ainu was smaller than those between the Okhotsk and other populations except the Nivkhi and Ulchi. Moreover, multidimensional scaling analysis (two-dimensional display, Fig. 4) of the genetic relationships among the 17 Asian populations based on $d_{A}$ distances showed that the Nivkhi, Ulchi, Negidal and Ainu were much closer to the Okhotsk people than the other Asian populations. These findings demonstrate that the Okhotsk people are closely related to modern populations distributed around the Sakhalin and downstream of the Amur River as well as to the Ainu people of Hokkaido.

\section{Discussion}

Six haplotypes identified (types 2, 5, 6, 10, 15, 16) were specific to the Okhotsk people (Table 1). This finding shows that the Okhotsk people were genetically differentiated from other Asian populations. On the other hand, identification of the other ten haplotypes (types 1, 3, 4, 7, 8, $9,11,12,13$ and 14) from the Okhotsk people implies a close genetic relationship between the Okhotsk people and other northeastern Asian populations. In particular, the Okhotsk people had higher genetic affinities with the Nivkhi and Ulchi among the compared northeastern Asian populations (Figs. 3, 4). The Nivkhi and Ulchi populations are currently distributed in areas geographically close to the Okhotsk culture sites (Figs. 1,2). Among haplotypes 12, 13 and 14 identified from 11 Okhotsk people, a unique 


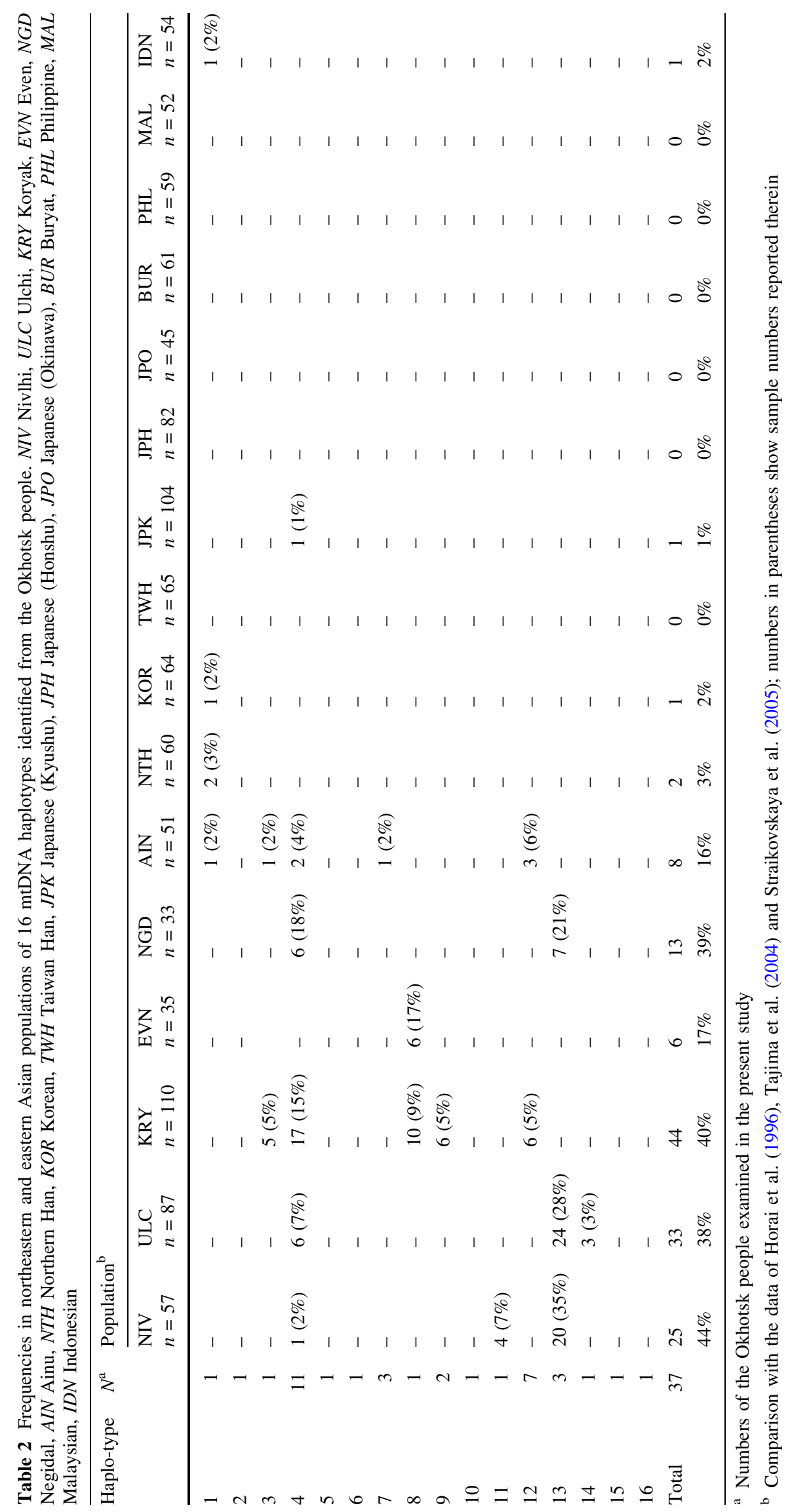



relationships among the 17 Asian populations including the distances $\left(d_{\mathrm{A}}\right)$ shown by the scale bar. The African population is used as outgroup. Numbers of individuals examined or cited are shown in parentheses. Bootstrap values of more than $50 \%$ are indicated near internal branches
Fig. 3 Neighbor-joining (NJ) Okhotsk, on the basis of genetic

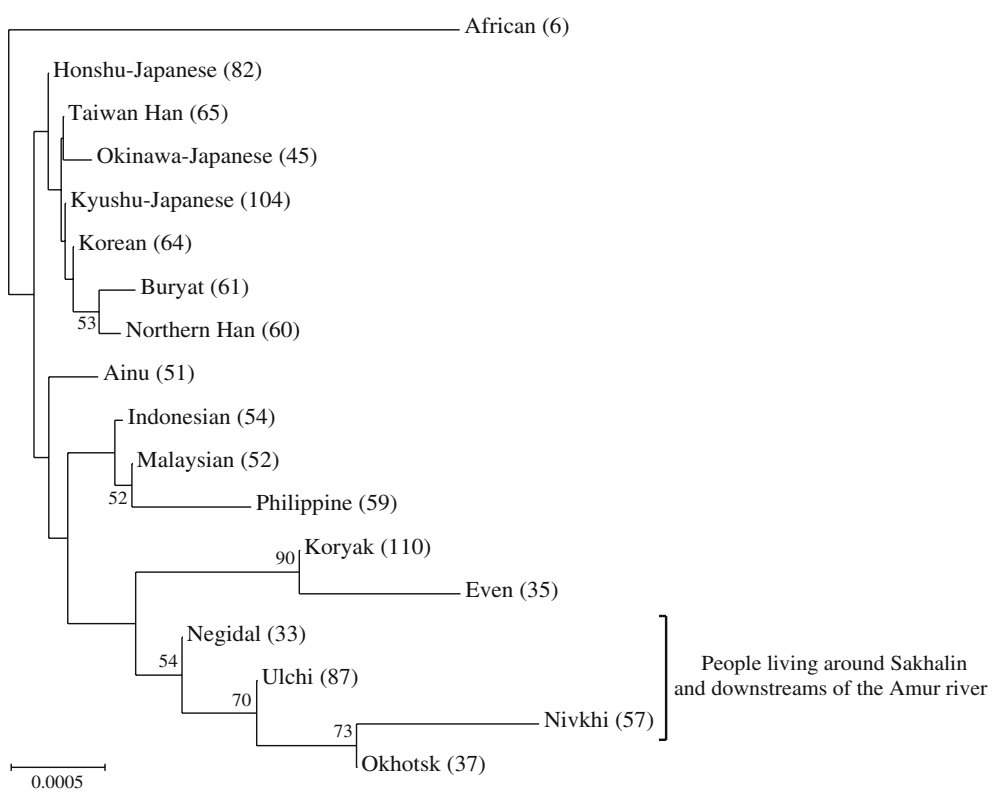

combination of four transitional mutations (16189C16231C-16266T-16519C for types 12, 13 and 14) was shared and regarded as the motif sequence for mtDNA haplogroup "Y1', reported by Kivisild et al. (2002). Recent studies have shown that most people with haplogroup Y1 are distributed in northern Asia and Siberia (Schurr et al. 1999; Kivisild et al. 2002). Moreover, Adachi et al. (2006) reported that haplogroup Y occurred in the Ainu of Hokkaido but not in the Jomon people of Hokkaido. In the present study, we found that the Okhotsk people shared haplogroup Y1 at a similar frequency $(30 \%, 11 / 37)$ to the Nivkhi (35\%, 20/57) and the Ulchi (31\%, 27/87) (Table 2). The result also suggests that the Okhotsk people are genetically closer to the Nivkhi and Ulchi because of the similarity in the frequencies of haplogroup Y1 between them. Moreover, haplogroup Y1 was shared also by the Ainu $(6 \%, 3 / 51)$ (Table 2). That the frequency of Y1 is higher in the Okhotsk people $(30 \%)$ than the Ainu $(6 \%)$ suggests gene flow from the Okhotsk people to the Ainu. In addition, other haplotypes clarified to haplogroup Y1 were found: for example, two types from two individuals of the Ulchi, two types from six individuals of the Nivkhi, and one type from seven individuals of the Ainu. When these numbers are included, the same direction of gene flow is still apparent. Tajima et al. (2004) examined mtDNA phylogeny of modern Asian people (not including the Okhotsk people) and reported that there was gene flow from the Nivkhi to the Ainu. The present study demonstrates that the Okhotsk people were an intermediate in the gene flow from the Nivkhi to the Ainu.

In previous morphological studies, Mitsuhashi and Yamaguchi (1961) reported that skeletons of the Okhotsk people had morphological characteristics similar to those of northeastern Asian people. In addition, Yamaguchi
(1974) and Ishida (1988, 1996) reported, based on cranial measurements, that the Okhotsk people were closer to populations that are currently distributed downstream of the Amur River. Moreover, Utagawa (2002) reported that evidence for the occurrence of bear-sending ceremonies, as seen in the Ainu culture, was found from archaeological sites of the Okhotsk culture. Rituals using brown bears are thought to be one proto-type of "Iomante,', which has been performed as a bear-sending ceremony in the Ainu culture. Therefore, archaeologists have generally assumed that the Okhotsk culture joined the Satsumon culture (eighth to fourteenth centuries; direct descendants of the Jomon people in Hokkaido) resulting in establishment of the Ainu culture. The direction of gene flow obtained in the present study is in agreement with the interpretation based on previous morphological and archaeological data. These facts demonstrate that the Okhotsk people could have originated from northeastern Asian populations such as the Nivkhi and Ulchi currently living around Sakhalin and downstream of the Amur River, and support the hypothesis that the Okhotsk people could have joined the Satsumon people resulting in the Ainu culture.

Kikuchi (2004) reported that walrus tusks excavated from archaeological sites of the Okhotsk culture could have been brought from the ancient Koryak culture to the Okhotsk culture, because walrus are currently distributed in the Arctic sea and the Bering sea. In the present study, the Okhotsk people were found to have some genetic affinities with the Koryak and the Even living around the Kamchatka peninsula (Table 2; Fig. 3). These facts suggest that there were genetic and cultural exchanges between the Okhotsk people and the Koryak and Even.

In conclusion, the present study has provided new insights towards further understanding the phylogenetic 


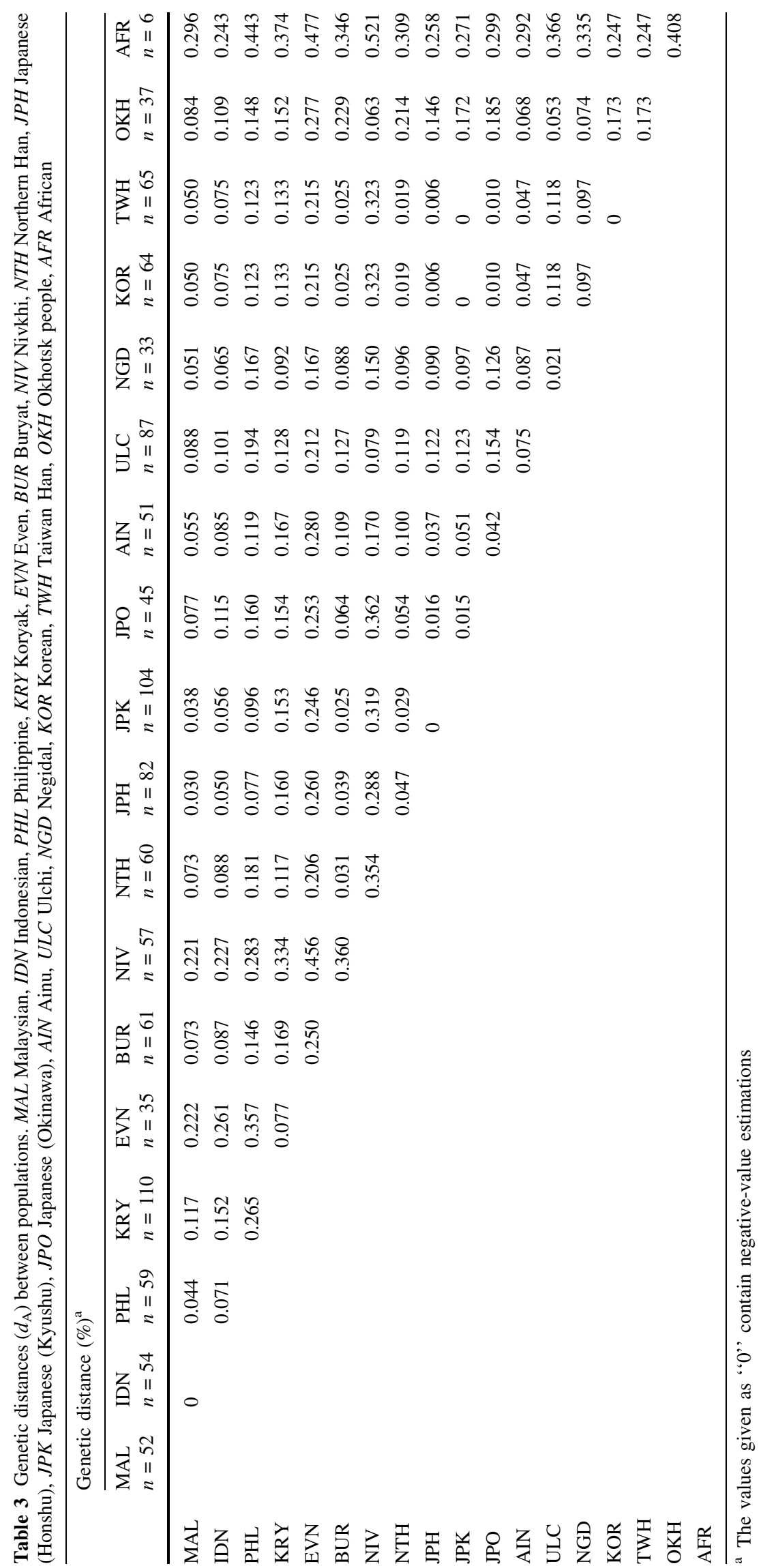




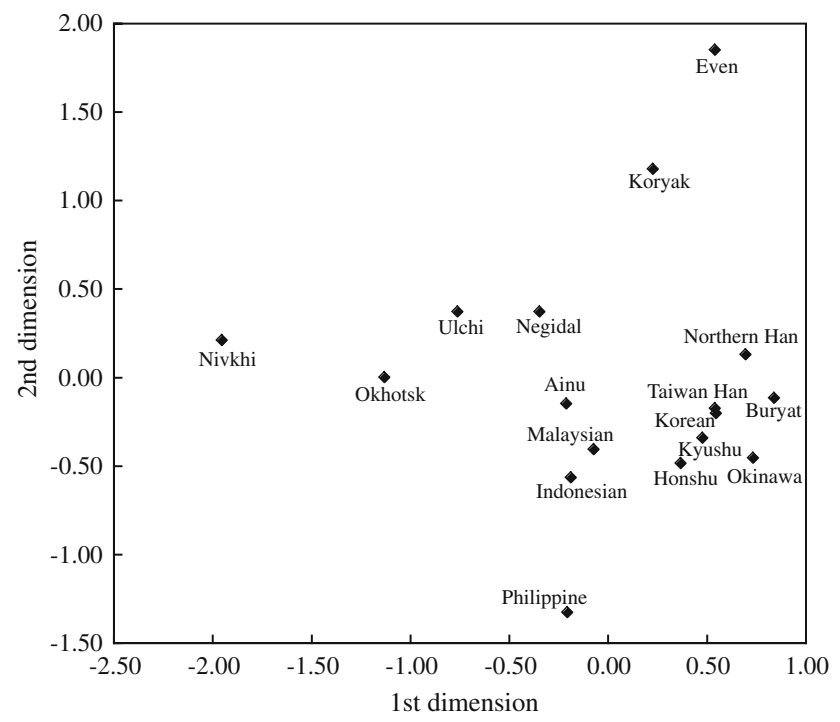

Fig. 4 Multidimensional scaling of the genetic relationships among the 17 Asian populations based on $d_{A}$ distances. The Okhotsk people are located near the positions of the Nivkhi, Ulchi, Negidal and Ainu

status of the Okhotsk people. Unique maternal genetic features of the Okhotsk people identified by ancient mtDNA analysis demonstrated their genetic differentiation and some genetic affinity with geographically neighboring modern populations such as the Nivkihi and Ulchi. The molecular phylogenetic data of the present study support the previous anthropological discussion based on morphological and archaeological data. For the next step, it will be necessary to investigate genetic features of paternal and biparental lineages using autosomal and Y-chromosomal markers for further clarification of the genetic origins of the Okhotsk people.

Acknowledgments We thank Prof. Naoko Takezaki (Kagawa University) for technical advice concerning directions of the SENDBS program. This study was supported in part by Grants-in-Aid for the Scientific Research from the Japan Society for the Promotion of Science and by the twenty-first Century Center of Excellence (COE) program "Neo-Science of Natural History" at Hokkaido University financed from the Ministry of Education, Culture, Sports, Science, and Technology, Japan.

\section{References}

Adachi N, Umetsu K, Takigawa W, Sakaue K (2004) Phylogenetic analysis of the human ancient mitochondrial DNA. J Archaeol Sci 31:1339-1348

Adachi N, Sakaue K, Dodo Y, Shinoda K, Umetsu K, Matsumura H, Ohshima N (2006) Mitochondrial DNA analysis of the Jomon and Epi-Jomon skeletons in Hokkaido, Japan (second report) (in Japanese). DNA Polymorph 14:86-90

Amano T (2003a) What is the Okhotsk culture? (in Japanese) In: Nomura T, Utagawa Y (eds) Epi-jomon and Okhotsk culture. Hokkaido Shimbun, Sapporo, pp 110-133

Amano T (2003b) The origin of bear ceremonialism (in Japanese). Yuzankaku, Tokyo
Anderson S, Bankier AT, Barrell BG, de Brujin MH, Coulson AR, Droujin J, Eperon IC, Nierlich DP, Roe BA, Sanger F, Schreier PH, Smith AJ, Staden R, Young IG (1981) Sequence and organization of the human mitochondrial genome. Nature 290:457-465

Felsenstein J (1985) Confidence limits on phylogenies: an approach using the bootstrap. Evolution 39:783-791

Horai S, Hayasaka K, Murayama K, Wate N, Koike H, Nakai N (1989) DNA amplification from ancient human skeletal remains and their sequence analysis. Proc Jpn Acad Ser B 65:229-233

Horai S, Murayama K, Hayasaka K, Matsubayashi S, Hattori Y, Fucharoen G, Harihara S, Park KS, Omoto K, Pan IH (1996) MtDNA polymorphism in East Asian populations, with special reference to the peopling of Japan. Am J Hum Genet 59:579-590

Ishida H (1988) Morphological studies of Okhotsk crania from Omisaki, Hokkaido. J Anthropol Soc Nippon 96:17-45

Ishida $H$ (1996) Metric and nonmetric cranial variation of the prehistoric Okhotsk people. Anthropol Sci 104:233-258

Kikuchi T (2004) Ancient culture on coastal areas of the sea of Okhotsk, 1st edn, (in Japanese). Hokkaido University Press, Sapporo

Kimura M (1980) A simple method for estimating evolutionary rates of base substitutions through comparative studies of nucleotide sequences. J Mol Evol 16:111-120

Kivisild T, Tolk HV, Parik J, Wang Y, Papiha SS, Bandelt HJ, Villems R (2002) The emerging limbs and twigs of the East Asian mtDNA tree. Mol Biol Evol 19:1737-1751

Kodama S (1948) Moyoro shell mound (in Japanese). Research Society of Hokkaido Ancient Culture, Sapporo

Kozintsev AG (1990) Ainu, Japanese, their ancestors and neighbors: cranioscopic data. J Anthropol Soc Nippon 98:247-267

Kozintsev AG (1992) Prehistoric and recent populations of Japan: multivariate analysis of cranioscopic data. Arctic Anthropol 29:104-111

Masuda R, Amano T, Ono H (2001) Ancient DNA analysis of brown bear (Ursus arctos) remains from the archeological site of Rebun Island, Hokkaido, Japan. Zool Sci 18:741-751

Mitsuhashi K, Yamaguchi B (1961) Anthropological study on the human remains excavated from Omisaki (Soya) I Mandible (in Japanese). Sapporo Med J 19:268-276

Nei M, Li WH (1979) Mathematical model for studying genetic variation in terms of restriction endonucleases. Proc Natl Acad Sci USA 76:5269-5273

Saitou N, Nei M (1987) The neighbor-joining method: a new method for reconstructing phylogenetic trees. Mol Biol Evol 4:406-425

Sambrook J, Fritsch EF, Maniatis T (1989) Molecular cloning: a laboratory manual, 2nd edn. Cold Spring Harbor Laboratory Press, New York

Schurr TG, Sukernik RI, Starikovskaya YB, Wallace DC (1999) Mitochondrial DNA variation in Koryaks and Itel'men: population replacement in the Okhotsk Sea-Bering Sea region during the Neolithic. Am J Phys Anthropol 108:1-39

Sneath PHA, Sokal RR (1973) Numerical taxonomy: the principles and practice of numerical classification. Freeman, San Francisco

Suzuki H (1958) Physische Anthropologie in Japan. Homo 9:37-47

Straikovskaya EB, Sukernik RI, Derbeneva OA, Volodko NV, RuizPesini E, Torroni A, Brown MD, Lott MT, Hosseini SH, Huoponen $\mathrm{K}$, Wallace DC (2005) Mitochondrial DNA diversity in indigenous populations of southern extent of Siberia, and the Origins of native American haplogroups. Ann Hum Genet 69:67-89

Tajima A, Hayami M, Tokunaga K, Juji T, Matsuo M, Marzuki S, Omoto K, Horai S (2004) Genetic origins of the Ainu inferred from combined DNA analyses of maternal and paternal lineages. J Hum Genet 49:187-193

Thompson JD, Higgins DG, Gibson TJ (1994) CLUSTAL W: improving the sensitivity of progressive multiple sequence 
alignment through sequence weighting, position-specific gap penalties and weight matrix choice. Nucleic Acids Res 22:46734680

Utagawa Y (2002) The world of the Okhotsk "bear festival" (in Japanese). In: Nishiaki Y, Utagawa Y (eds) Another World of the north. The University of Tokyo Press, Tokyo, pp 106113

Vigilant L, Stoneking M, Harpending H, Hawkes K, Wilson AC (1991) African populations and the evolution of human mitochondrial DNA. Science 253:1503-1507
Walsh PS, Metzger DA, Higuchi R (1991) Chelex 100 as a medium for simple extraction of DNA for PCR-based typing from forensic material. Biotechniques 10:506-513

Yamaguchi B (1974) Prehistoric people of Hokkaido (in Japanese). Quat Res 12:257-264

Yoneda M, Shibata Y, Tanaka A, Uehiro T, Morita M, Uchida M, Kobayashi T, Kobayashi C, Suzuki R, Miyamoto K, Hancock B, Debden C, Edmonds JS (2004) AMS 14C measurement and preparative techniques at NIES-TERRA. Nucl Instrum Methods Phys Res B223-224:116-123 